(d) Measurements of botanical or other objects under low power.

The most obvious virtue is portability (waistcoatpocket type).

Any scale may be employed. That actually in use is one of ro millimetres divided into fifths of a millimetre. With estimation to a tenth of an interval a final reading to $0.02 \mathrm{~mm}$. ( $=0.0008 \mathrm{inch})$ is obtained. The actual divisions are on the outer side of the glass graticule and so practically in contact with the object under examination. Parallax is so small as not to be observable.

If a Kellner type of eyepiece is used the graduations could be marked directly on the outer surface of the field lens. This gives a still simpler optical system.

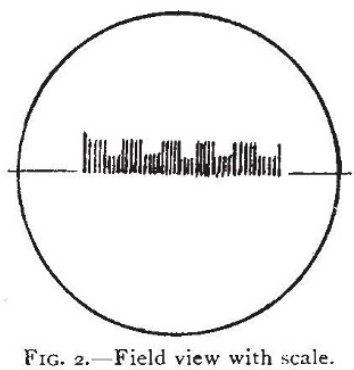

It is not claimed that this is a novelty, but it is certainly not well known.

The mechanical engineer of the India Store Department, Mr. A. L. Haas, while investigating Brinnell impressions, consulted us with reference to a very simple type of measuring device. The result is described above.

Any optical firm could make such a device. The original instrument was made, at the authors' request, by Messrs. W. Ottway and Co., Ltd., under the supervision of Mr. Wood, of the firm's optical department, who devised a scale in which alternate millimetre intervals were divided by long and short lines (Fig. 2).

T. F. CONNOLLY.

E. H. Coumbe.

\section{Inheritance of Characters acquired by Grafting.}

IN NATURE of February 2, p. I74, a brief account is given of L. Daniel's experiments in which an artichoke was grafted on a sunflower. The seeds of the transplanted artichoke yielded a series of plants differing from each other in several respects. This result is claimed by the author as a case of inheritance of characters acquired by grafting. Now artichokes very seldom set seed-personally, I have never seen a case ; but as there exist several varieties of this species, it is highly probable that many, if not all, artichokes are heterozygous in many respects. Grafting very often causes the scion to produce flowers and seed; it seems very natural that the transplanted artichoke was influenced in that waya physiological action of purely phenotypical nature without the slightest influence upon the genotypical constitution of the scion; the differences between the individuals of the progeny are here without doubt a consequence of the heterozygous nature of the scion.

I must confess that the great bulk of indications claimed as cases of the alleged inheritance of acquired characters show an astonishing lack as to critical judgment-creed in the place of science.

Copenhagen, March Io. W. JOHANNSEN.

\section{The Singing of Wires in a Wind.}

THE following observation may be of interest in connexion with the singing of wires in a wind. A four-pronged toasting-fork was waved backwards and forwards through the air. It was found that if the plane of the prongs was in the direction of motion, a singing noise was produced, but that if the plane of the prongs was perpendicular to the direction of motion and the fork was moved at the same speed through the air, the singing was practically inaudible. The prongs were $8 \mathrm{~cm}$. long, $0.25 \mathrm{~cm}$. diameter, and they were spaced $2 \cdot 2 \mathrm{~cm}$. apart.

The resistance of a wire when it is moved through air, and also the singing noise produced by its motion, are both due to eddies which are formed in its wake It seems curious, therefore, that when several wires are arranged so that they shield one another and thus reduce their total resistance, the singing noise is thereby greatly increased instead of being reduced.

Trinity College, Cambridge,

G. I. TAYLOR. March 15.

\section{Underblown Pipes.}

As a result of careful experiments conducted by Messrs. G. Subrahmaniam and D. Gunnaiya, it has been found that the behaviour of underblown pipes presents many features of remarkable interest. The following is a brief account of the results obtained with four wooden pipes ranging over an octave $(256,320,384$, and 5 r 2$)$.

The behaviour of the 256 pipe, which is the gravest of the set, is identical with that described by the late Lord Rayleigh (Phil. Mag., I3, I882); that of 320 showed a slight difference, while in the other two the difference became marked at least in one respect. In all the pipes a note distinctly lower in pitch as well as in intensity than the fundamental makes its appearance at a pressure of a few millimetres, and the minimum pressure to start this note increases with increase of pitch. The note gets considerably sharper than the fundamental as the pressure rises, and ceases at pressures which are also higher for higher pitches.

In the two lower pipes a note slightly lower than the octave starts a little before, or when, the fundamental ceases. In the higher pitches, however, instead of the octave, a period of silence ensues. In fact, this octave-tone is very feeble even in the 320 pipe and is obtained with difficulty. The periods of silence in the two higher pipes are followed by tones which are, to start with, a little flatter than the fundamentals. The pressures at which the normal tones commence are also higher for the higher frequency pipes.

In the lower pipes the octave-tones, which started as the underblown fundamentals disappeared, rise with pressure and cease, giving rise to normal tones immediately in the case of 256 pipe and preceded by a very short period of silence in the case of 320. The entire absence of the octave counterpart in the two higher pipes distinguishes their behaviour from the lower ones and that described by Lord Rayleigh. This suggests that the octave counterpart appears for pipes lower than a particular limiting frequency. The difficulty experienced in the case of the 320 pipe also suggests that it is very near the limiting frequency.

A. L. Narayan.

H.H. The Maharajah's Research Laboratories, Vizianagaram.

$$
\text { NO. } 284 \text { I, VOL. I I } 3]
$$

